\title{
Educar para a Saúde no Século XXI: Falas de Professores
}

\author{
Education for Health in the XXI Century: Speech Teachers \\ C. A.Vasconcelos ${ }^{1,2 *} ;$ J.W. Santos ${ }^{2}$ \\ ${ }^{1}$ Departamento de Educação da Universidade Federal de Sergipe 49100-000, São Cristóvão-SERGIPE, Brasil. \\ ${ }^{2}$ Programa de Pós-graduação em Ensino de Ciências e Matemática/Universidade Federal de Sergipe 49100-000, São \\ Cristóvão-SERGIPE, Brasil.
}

*geopedagogia@yahoo.com.br

(Recebido em 26 de outubro de 2015; aceito em 06 de novembro de 2016)

\begin{abstract}
Educar em tempos de alta tecnologia é certamente um dos mais instigantes desafios para os profissionais da educação no século XXI. O presente trabalho procurou investigar como os profissionais da educação da rede de ensino estadual de Sergipe, especificamente professores de educação física, desenvolvem suas ações pedagógicas voltadas à educação para saúde. Analisamos a formação acadêmica deles, seus planos de curso e como estes concebem a saúde e a educação para saúde. Optamos por conceber a saúde a partir de uma visão holística, a qual é compreendida como um conjunto composto por diferentes esferas, e a partir de então discutir com os entrevistados sobre a intervenção deste no meio escolar onde atuam. Estamos certos de que ações para o desenvolvimento da educação para a saúde no âmbito escolar não apenas são pertinentes como são institucionalmente orientados para sua efetivação, os quais, certamente, promoverão mudanças qualitativas e quantitativas frente a adoção de um estilo de vida mais saudável por parte dos educandos.

Palavras-Chave: Educação Física. Educação para Saúde. Prática e Formação Docente
\end{abstract}

Educating in high-tech times is certainly one of the most exciting challenges for education professionals in the $21^{\text {st }}$ century. This study aimed to investigate the education professionals of the state school system of Sergipe, specifically physical education teachers, develop their pedagogical actions aimed at health education. It was analyzed academic formation, course plans and how they conceive of health and health for education. We chose to conceive of health from a holistic view, which is understood as a set composed of different spheres, and from then discussed with respondents on this intervention in schools where they work. We are sure that actions for the development of health education in schools are not only relevant as they are institutionally oriented its effectiveness, which will certainly promote qualitative and quantitative changes ahead adopting a healthier lifestyle by of learners.

Keywords: Physical education. Health Education. Practice and Teacher Training

\section{INTRODUÇÃO}

Educar para a saúde deve ser percebido como um dos grandes desafios da educação contemporânea, em tempos de acesso à alta tecnologia por parte considerável da população e com o advento e consequente febre das redes sociais, que, de certa forma, distanciam as pessoas do contato, do presencial.

Torna-se imprescindível despertar nos educandos a necessidade de se adotar hábitos saudáveis voltados não apenas para a prática regular de atividades físicas, mas também para a higiene corporal, alimentação saudável, investimento pessoal e relacionamentos sociais.

Ao concebermos uma educação para a saúde de forma mais ampla, global, automaticamente estamos explicitando que compreendemos esta como um conjunto sincrético de diferentes esferas que convivem com mútua interdependência, ambas numa busca constante de equilíbrio, não apenas para o organismo vivo - o qual biologicamente somos, mas também para o corpo biopsicossocial, o qual fizemos historicamente por se relacionar "[...] dentro de um contexto sociocultural" (BRASIL, 1998, p. 29) [1].

Sendo a escola o local por excelência de trato formal com o conhecimento, podemos então afirmar que cabe aos seus educadores a devida formação, inicial e continuada, para o trabalho didático-pedagógico transdisciplinar visando à promoção da saúde, pois, como afirma Paulo Freire: 
Se a educação sozinha não transforma a sociedade, sem ela tampouco a sociedade muda. Se a nossa opção é progressista, se estamos a favor da vida e não da morte, da equidade e não da injustiça, do direito e não do arbítrio, da convivência com o diferente e não de sua negação, não temos outro caminho senão viver plenamente a nossa opção. Encarná-la, diminuindo assim a distância entre o que fizemos e o que fazemos [2].

Desta feita, é importante pensarmos na formação humana, e nesta, a continuada. Porém, como pensarmos em formação continuada para o professor se os sistemas educacionais não promoverem as condições necessárias para que este mantenha busca constante ao conhecimento, à pesquisa, a sua melhoria profissional? Como desenvolver perspectivas de trabalho docente para o ensino da saúde sem considerar a estrutura curricular dos cursos de formação de professores pelas instituições de educação superior? E a escola de ensino fundamental e médio tem estimulado o fomento para a cultura da saúde compreendida de forma holística?

Necessitaríamos de inúmeras discussões e não apenas de uma breve incitação à temática que está sendo abordada neste trabalho. Importante ressaltar que se é uma necessidade da sociedade e obrigatoriedade da educação em oferecer o ensino da promoção da saúde na educação formal, aqui em específico, priorizamos o ensino médio, não podemos conceber que esta responsabilidade seja exclusivamente do professor, mas de toda a conjuntura sociocultural e econômica que envolve a escola.

Para tal, tornar-se necessário levantar essa problemática à luz de diferentes prismas, debatendo com os diversos personagens envolvidos com o problema do ensino da saúde, entre eles os educadores, os educandos, os sistemas de educação, a formação de professores e as políticas públicas para à educação. Mas, por limitação, procuraremos aqui despertar a atenção apenas para a necessidade de mantermos a discussão acerca do ensino da educação para a saúde de forma holística e não apenas biologista, a qual historicamente reduziu a saúde apenas sob o prisma reducionista das ciências naturais.

Assim, este trabalho desenvolveu-se na região sul do Estado de Sergipe, sendo este o universo de nossa pesquisa, e nossa amostra composta por profissionais da Educação Física, um total de 04 (quatro) professores, ambos do sexo masculino, lotados em colégios da rede estadual de ensino, especificamente dos municípios de Tobias Barreto (Colégio Estadual Maria Rosa de Oliveira), Itabaianinha (Colégio Estadual Monsenhor Olímpio Campos), Arauá (Colégio Estadual Manuel Bomfim) e Pedrinhas (Colégio Estadual Dr. Jessé Fontes), estes distantes cerca de $120 \mathrm{~km}$ em média da capital, Aracaju.

Nossa pesquisa, quanto à abordagem, configura-se como qualitativa; exploratória por ter como objetivo a investigação de dados referentes à prática dos educadores da rede pública estadual de ensino do estado de Sergipe referente ao ensino da promoção da saúde; e estudo de campo por ter sido "[...] desenvolvida por meio da observação direta das atividades do grupo estudado e de entrevistas com informantes para captar suas explicações e interpretações do que ocorre no grupo" (GIL, 2002, p. 53) [3]. Durante todo o trabalho de coleta dos dados procuramos manter uma postura analítica sobre a ação docente dos entrevistados frente à temática do ensino da saúde no nível médio [4].

Nossos objetivos foram: consultar bibliografia especializada na temática do ensino da saúde; pesquisar a formação acadêmica e continuada dos professores de educação física para o ensino da promoção da saúde; analisar as políticas públicas de educação para a promoção da saúde; observar a utilização da temática do ensino da promoção da saúde pelos profissionais de educação pública da rede estadual de Sergipe em seu fazer didático-pedagógico.

Para coleta dos dados, fizemos uso de três procedimentos metodológicos distintos: 1. Pesquisa bibliográfica na literatura científica sobre a temática do ensino da saúde; 2 . Análise das políticas públicas de fomento à educação para a saúde - ainda que de forma sutil por conta das limitações deste trabalho; 3. Realização de entrevista semiestruturada aplicada aos educadores, tendo sido estes questionados sobre sua formação acadêmica, respectiva estrutura curricular e formação continuada, seus planos de ensino ou de curso com o organograma dos conteúdos programáticos, 
considerando as três dimensões dos conteúdos (conceituais, atitudinais e procedimentais), conforme recomendam os PCN [1].

Nessa ótica, Libâneo (2002) [5] aponta que o trabalho de Educação Física é imprescindível e de extrema importância para a formação para a saúde dos nossos jovens. Cabe não aos profissionais de educação física, mas a todos os educadores fazerem uso das mais diferentes ferramentas didático-pedagógicas para o desenvolvimento da promoção da saúde. Para ele: "A pedagogia e a educação física têm muito a oferecer uma à outra porque se há uma dimensão física da educação, há uma dimensão pedagógica da educação física" (LIBÂNEO, 2002, p. 118) [5].

\section{O ENSINO PARA A SAÚDE}

\subsection{Saúde}

Historicamente, o termo saúde sempre teve bastante relevância dentro das sociedades humanas, não obstante compreendermos que sempre travamos uma incansável busca por viver mais e melhor. No entanto, torna-se necessário frisar que devemos compreender o quão ilusório e infundado é o alcance pleno do estado de saúde.

Segundo Sabroza (1994, p. 112) [6] a saúde pública e/ou saúde coletiva pode ser "[...] definida genericamente como campo de conhecimento e de práticas organizadas institucionalmente e orientadas à promoção da saúde das populações". Czeresnia (1999) [7] enfatiza que definir saúde e doença torna-se difícil por estas serem de cunho subjetivo e estarem atreladas às percepções e interpretações dadas por cada um ao sentir-se bem ou estar debilitado. Por exemplo: alguém pode ser portador de uma doença crônica e, no entanto, declarar-se saudável, apesar de ser portador de uma patologia; ou alguém pode ter todas as características de ser saudável e manifestar depressão.

A própria definição da Organização Mundial da Saúde (OMS) não consegue mais encontrar fundamentação teórico-científica e consequentemente se sustentar ao tentar afirmar que: "A saúde é um estado de completo bem-estar físico, mental e social, e não consiste apenas na ausência de doença ou de enfermidade" (HWO, 1946, p. 01). Definir saúde necessita, acima de tudo, de percepção da própria subjetividade inerente ao estado de ser ou sentir-se saudável.

Outra tentativa de definição sobre saúde é apresentada por Bouchard et al, e nos parece mais adequado à subjetividade inata do termo. Apesar de enfatizarem que saúde é o 'estado geral de equilíbrio no indivíduo', os mencionados autores relativizam que ela se apresenta como um continuum com polos, positivos e negativos. Os primeiros estariam ligados à capacidade de reagirmos positivamente em face dos desafios, sejam eles quais forem; já os negativos nos predisporíam à morbidade e num outro extremo à mortalidade [8].

Tratando da mesma questão Darido et al., (2001, p. 01) [9] ressalta:

O conceito de saúde apresenta limitações quando se pretende defini-lo de maneira estanque e conclusiva. Isto porque quando se fala em saúde não podemos deixar de considerar seus fatores de influência e determinação: o meio ambiente, os aspectos biológicos, socioeconômicos, culturais, afetivos e psicológicos.

Fica-nos clara a necessidade de relativizarmos quando formos realizar uma tentativa de conceituação do que é saúde, visto ser esta uma manifestação de subjetividade, inserida na diversidade sociocultural e econômica dos grupos sociais, considerando ainda a individualidade biológica de cada um.

\subsection{Promoção da Saúde}

$\mathrm{O}$ verbo promover nos remete à ação de fomentar, dar impulso, estimular. Concebido dessa forma, o promover compreende uma ação mais ampla que o prevenir, sendo que o primeiro se restringe à pura precaução, enquanto que a segunda engloba um conjunto de ações a favor de algo ou alguém.

Promoção da saúde é definida como o conjunto de ações, medidas e estratégias que "não se dirigem a [combater] uma determinada doença ou desordem, mas servem para aumentar a saúde e 
o bem-estar gerais" (LEAVELL, CLARCK, 1976) [10]. Essas estratégias de promoção buscam enfatizar mudança qualitativa das condições de vida e de trabalho das pessoas, considerando que conformam a estrutura subjacente aos problemas de saúde, demandando uma abordagem intersetorial, ou seja, destacando a importância da articulação entre várias instituições no caso da promoção da saúde. Poderíamos afirmar que, na escola, o ensino para a formação da saúde apenas se consubstanciaria com o trabalho interdisciplinar de todos os profissionais da educação, considerando que o estado de saúde é uma manifestação multifacetada.

\subsection{Qualidade de Vida}

Quando nos referimos ao termo qualidade, segundo sua origem etimológica, este pode estar se referindo a algo bom ou ruim; mas ao anexá-lo ao substantivo vida, a expressão qualidade de vida toma a conotação de níveis ótimos de saúde, bem-estar, felicidade, satisfação, etc.

Muitas são as abordagens que buscam classificar os estudos sobre a qualidade de vida. Como essa também perpassa pelo viés da subjetividade, da percepção própria, torna-se difícil uma definição clara e unânime do que possa vir a ser qualidade de vida. Day e Jankey (1996) [11] nos apresentam os estudos sobre a qualidade de vida a partir de quatro abordagens principais: a) social - que, segundo eles, deu origem à expressão quando muitos políticos começaram a fazer uso desta em seus pronunciamentos a partir da década de 1960; b) psicológica - onde os elementos subjetivos determinam o entendimento sobre o que venha a ser satisfação, podendo ser compreendida coletiva ou individualmente; c) biomédica - refere-se à ação dos profissionais da saúde em promoverem melhorias nos níveis de saúde dos seus clientes, ou ampliando sua sobrevida; geral ou holística baseia-se na compreensão multidimensional da qualidade de vida.

Tendo em vista a multiplicidade de conceitos sobre o que possa vir a ser qualidade de vida, utilizaremos o da Organização Mundial da Saúde (OMS) por considerarmos este o mais apropriado. Para a OMS, a qualidade de vida é "[...] a percepção do indivíduo sobre a sua posição na vida, no contexto da cultura e dos sistemas de valores nos quais ele vive, e em relação a seus objetivos, expectativas, padrões e preocupações" (WHO, 1995, p. 1405) [12]. Para Araújo e Araújo, podemos ainda delimitar a qualidade de vida em dois tipos: qualidade de vida não relacionada à saúde (QVNRS) e qualidade de vida relacionada à saúde (QVRS). Para eles, a QVNRS estaria mais ligada às questões socioambientais, e a "[...] QVRS representa a parte da qualidade de vida ligada diretamente à saúde do indivíduo” (ARAÚJO \& ARAÚJO, 2000, p. 195) [13].

\subsection{Formação de Professores e Políticas Públicas para o Ensino da Saúde no Brasil}

O Brasil mantém desde o ano de 2009 a política de formação de professores instituída pelo Decreto 6755/2009. Essa estratégia faz parte do Plano de Desenvolvimento da Educação (PDE), em vigor desde abril de 2007, e se articula com a Política Nacional de Formação de Professores. Para consubstanciar a ação, um pacto de colaboração entre União, estados e municípios foi estabelecido para a consolidação do plano estratégico de formação inicial para os professores que atuam nas escolas públicas.

Como problematizamos anteriormente, não podemos centralizar apenas na figura do professor a total responsabilidade do ensino da saúde. Convém novamente ressaltar que esta deve ser compreendida como a soma de diferentes instituições, sendo delegada a cada uma sua respectiva obrigação: desde a promoção de cursos de formação continuada para os educadores, até a ação articulada entre os diferentes setores do serviço público, a qual denominamos de intersetorialidade.

A origem das políticas de saúde escolar remonta ao final do século XVIII e o início do século XIX, quando o médico alemão Johann Peter Frank (1745-1821) elaborou o System einer Vollständigen Medicinischen Politizei, que ficou conhecido posteriormente como Sistema Frank. A ele é dado o mérito de pai da educação escolar para a saúde, haja vista ter sido ele que sistematizou naquela época toda a atenção que deveria ser dispendida aos escolares: desde a saúde física e mental até a prevenção de acidentes e instalações adequadas [14]

No Brasil, sob o Decreto $\mathrm{n}^{\circ}$ 6286, de 5 de dezembro de 2007, foi instituído em todo o território nacional o Programa Saúde na Escola (PSE), que tem como objetivo principal "contribuir com a formação integral dos estudantes da rede pública de educação básica por meio de ações de 
prevenção, promoção e atenção à saúde" (BRASIL, 2007, p. 01) [15]. A finalidade desse programa é promover a articulação entre as ações do Sistema Único de Saúde (SUS) e as ações da educação básica. Convém ressaltar que essa correlação deverá se dar através da ação dialógica, pensada e planejada, e não apenas na intervenção passiva dos profissionais da saúde no interior da escola sem considerar o agente formador e transformador de opinião, que é o professor.

Ainda na década de 1970, na Escola de Saúde da Universidade de São Paulo (USP), a professora Ruth Sandoval Marcondes já dissertava sobre "Educação em Saúde na Escola", cujos objetivos, segundo ela, seriam os elencados a seguir:

a. Contribuir para a proteção e promoção da saúde do escolar, proporcionando-lhe um ambiente físico e emocional adequado ao seu crescimento e desenvolvimento, ajudando-o a compreender a importância dos exames periódicos de saúde, estimulando-o a utilizar os recursos de saúde da comunidade, concorrendo para a prevenção e controle das doenças transmissíveis.

b. Desenvolver um currículo orientado no sentido de atender às necessidades e interesses do escolar, proporcionando-lhe experiências de aprendizagem que o habilitem a aplicar as descobertas científicas em benefício de sua saúde.

c. Levar o escolar a compreender a necessidade da sua participação para o equacionamento dos problemas pessoais de saúde, de sua família e de sua comunidade (MARCONDES, 1971) [16].

Observa-se que no momento histórico mencionado, já existia a preocupação não apenas com a saúde vista pelo olhar reducionista das ciências biológicas, como também com a compreendida de maneira holística, global.

Compreendendo a educação e a saúde como direitos universais, garantidos na Constituição Federal de 1988, que em seu artigo 191 desta versa que a "[...] saúde é direito de todos e dever do Estado, [...]", e seu artigo 205 reza que a educação é "direito de todos e dever do Estado e da família, [...]" (BRASIL, 1988, p. 41) [17]. Não esquecendo que esses direitos foram reafirmados não apenas na LDB 9394/96, mas também nos Parâmetros Curriculares Nacionais (PCN), que devem ser compreendidos como propostas de subsídios aos profissionais de educação, e estes profissionais devem procurar tematizar os diferentes conteúdos, considerando suas características (conceituais, procedimentais e atitudinais) para uma melhor compreensão por parte dos educandos.

Apresentado dessa forma, acredita-se que esteja claro para nós profissionais da educação sobre nossa responsabilidade frente ao ensino para a saúde, devendo este ser trabalhado de preferência inter ou transdisciplinarmente, promovendo a contribuição das diferentes áreas do conhecimento humano presentes na Educação Básica para o fomento da educação para a saúde, e que consigamos ainda conexões intersetoriais com profissionais da saúde, e por que não com demais profissionais do poder público, promovendo assim uma cultura de educação para a saúde pela abordagem holística.

\subsection{Tecnologias da Informação e Comunicação (TIC)}

Estamos vivendo tempos de uma grande revolução: nos costumes, nos modos, nas ações. Mudanças bruscas, constantes e persistentes em nossa forma de falar, ouvir, pensar, vestir, comportar, interagir, etc. estão a todo momento em intensa metamorfose. Se para melhor ou pior, talvez ainda não podemos qualificar - ou talvez já -, mas inevitavelmente promoverão mudanças irreversíveis em nosso modo de compreender, tudo isso que nos torna humanos: a cultura.

Nossa forma de nos comunicar está passando por uma transformação de proporções gigantescas: reduzimos distâncias, derrubamos fronteiras, transpomos o texto, a mente, o corpo; podemos estar aqui e agora, e ao mesmo tempo, em diferentes lugares com as mais diferentes pessoas, das mais diferentes culturas e linguagens. A internet, desenvolvida a partir de 1950, também passou por esse processo de transformação, e hoje temos a Web 2.0. Alguns já falam em Web 3,0. Tudo isso 
promove um gigantesco boom no processo de globalização desencadeado entre os séculos XIV e $\mathrm{XV}$ com as grandes navegações.

Reforçando essa questão Castells (2001, p.60) acrescenta:

[...] a Internet não é apenas uma ferramenta de comunicação e de busca, processamento e transmissão de informações que oferece alguns serviços extraordinários; ela constitui, além disso, um novo e complexo espaço global para o aprendizado e ação educacional.

Essas mudanças de comportamento na sociedade pós-moderna também trouxeram inevitavelmente para a educação a necessidade de mudanças de paradigma no processo de ensinoaprendizagem, em especial na relação entre seus principais protagonistas: o professor e seus alunos. Nós e nossos alunos não somos mais os mesmos de dez, cinco anos atrás. Sendo assim, torna-se necessário que nós, enquanto profissionais da educação, procuremos ser antes de qualquer coisa um eterno pesquisador, e nesse processo contínuo de inquietude incide a necessidade da formação continuada.

Dominar as novas tecnologias tornou-se atualmente, para os profissionais da educação, uma necessidade até mesmo para seu reconhecimento dentro da escola por seus alunos, visto serem as TIC elementos de fundamental importância para as sociedades pós-modernas, sem levar em consideração o inevitável reconhecimento que essas tecnologias têm entre os jovens, aqueles aos quais alguns autores chamam de geração y, nossos alunos, os nativos digitais; nós, os imigrantes digitais (PRENSKY, 2001).

Compreendido dessa forma:

O professor precisa adquirir habilidades técnicas e pedagógicas, respondendo aos grandes desafios que envolvem essa área de uso do computador na educação, que é justamente a combinação do técnico com o pedagógico (MERCADO, 2002, p. 139) [20].

Ainda reforçando esta questão, Silva (2009, p.86) [21] entende que a internet dispõe de um potencial inesgotável, e os educadores devem estar atentos a isso, pois:

Na cibercultura os professores podem lançar mão da potencialidade da internet para abrir novos espaços de participação coletiva. Eles podem experimentar isso na sala de aula presencial e online e preparar o aluno para a geração digital, para sua atuação no novo espaço de manifestação da cidadania.

Isso que ele chama de cibercultura remete-nos à civilização da conectividade, do aqui e agora, e ao mesmo tempo onde se queira estar.

Adentrando nessa questão, Levy diz que o ciberespaço,

[...] é o principal canal de comunicação e suporte de memória da humanidade a partir do início do século XXI; novo espaço de comunicações, de sociabilidade, de organização e de transação, mas também o novo mercado da informação e do conhecimento que tende a tornar-se a principal infraestrutura de produção, transação e gerenciamento econômicos. O ciberespaço é o hipertexto mundial interativo, onde cada um pode adicionar, retirar e modificar partes dessa estrutura telemática, como um texto vivo, um organismo autoorganizante. (LÉVY, 1999) [22].

A essas novas e até usuais "ferramentas tecnológicas" que podem e devem ser utilizadas no processo de ensino-aprendizagem dá-se o nome de TIC - tecnologias da informação e comunicação, que, segundo Ramal (2008, p. 58) [23] são concebidas "[...] como redes de produção 
de conhecimentos e de aprendizagem, mais do que como meros instrumentos de intercâmbio de informação, pois são recursos imprescindíveis para a gestão do conhecimento".

Esses recursos agora não apenas informarão, tornando seus expectadores personagens passivos do processo; mas atualmente, com as inovações das TIC, promovem interação, comunicação, compartilhamento, tornando-nos agentes ativos do processo.

Segundo Mercado et al., (2012, p. 111) [24]"as interfaces da web 2.0 centram-se em possibilitar e promover trocas de conteúdo, participação, interação e colaboração dos envolvidos", uma verdadeira revolução nos modos de informação e comunicação.

\section{RESULTADOS E DISCUSSÃO}

Nossa amostra foi composta de quatro profissionais de Educação Física, todos funcionários efetivos da rede pública estadual de ensino do Estado de Sergipe, lotados em turmas de ensino médio dos diferentes colégios da rede pública no sul do estado.

Caracterizaremos, os entrevistados por algarismos numéricos, cada um representando um professor das instituições de ensino (IE) analisadas: 1 - Colégio Estadual Maria Rosa de Oliveira - Tobias Barreto; 2 - Colégio Estadual Monsenhor Olímpio Campos - Itabaianinha; 3 - Colégio Estadual Manuel Bomfim - Arauá; 4 - Colégio Estadual Dr. Jessé Fontes - Pedrinhas.

\subsection{Análise da Formação Acadêmica e Continuada}

Todos os entrevistados participantes de nossa amostra se encontram devidamente regularizados frente à relação formação-atuação, uma vez que são todos são graduados em Educação Física e atuam exclusivamente em suas áreas específicas na educação básica e foram ingressantes no magistério a partir de concurso público. Destes profissionais, dois foram formados em instituições privadas e dois por instituições públicas; aqueles provenientes de instituições privadas não realizaram posteriormente cursos de formação continuada e aqueles provenientes de instituições públicas, realizaram posteriormente cursos de especialização, um em Arte e Educação e o outro em Psicopedagogia.

\subsection{Quais disciplinas da grade curricular de sua formação acadêmica ou continuada enfatizaram o ensino da saúde?}

O professor da IE1 cursou as disciplinas Educação e Saúde Corporal, Atividade Física, Nutrição e Saúde Coletiva, todas em sua graduação; o professor da IE 2 cursou, em sua graduação, a disciplina Crescimento e Desenvolvimento Humano, mas, segundo ele, "a maioria das disciplinas estão ligadas direta ou indiretamente com a promoção da saúde"; o professor da IE 3 cursou Componentes e Fundamentos da Atividade Física, Prevenção e Segurança na Atividade Física; IE 4 cursou Componentes Funcionais da Atividade Física, Prevenção e Segurança na Atividade Física, Cineantropometria e Consciência Corporal.

Em todos os casos, a saúde é concebida como viés das ciências biológicas, e os professores em seus planejamentos não descrevem a saúde como uma relação, mas somente como um item isolado.

\subsection{No seu plano de ensino é dedicado trabalho para o ensino da saúde? Em qual perspectiva?}

O professor IE 1 afirma contemplar "dois conteúdos por unidade, desenvolvendo-os de forma que consiga aliar teoria e prática e que sejam condizentes com a realidade dos alunos, tomando como norte os Parâmetros Curriculares Nacionais"; o IE 2 afirmou trabalhar a promoção da saúde e os respectivos benefícios do estilo de vida ativo e alimentação adequada; o IE 3 mantém em seu planejamento o trabalho com a "atividade física e saúde, vícios posturais e doenças crônicodegenerativas"; IE 4, por suas próprias palavras, afirma trabalhar com "conceitos teóricos e vivências corporais que possam ampliar o conhecimento dos alunos sobre os determinantes da saúde: autocuidado e relação com o meio em que se vive". 
Observemos que todos os entrevistados expressam, ainda que um pouco implícito, o trabalho didático-pedagógico dentro das três categorias dos conteúdos: conceituais, procedimentais e atitudinais, recomendado pelos PCNs (BRASIL, 1999). No entanto, é dada ênfase ao ensino da saúde pela perspectiva biológica, não considerando as demais esferas que em conjunto possam determinar o ser saudável. O professor da IE 4 no entanto, explicita sua preocupação em tratar a saúde como uma relação com o meio em que se vive, demonstrando assim uma provável percepção da saúde pelo viés da totalidade.

\subsection{Como são utilizadas as TIC em seu fazer didático-pedagógico? Poderia nos explicar?}

Quando foram questionados sobre a utilização das TIC em sala de aula os quatro docentes quase que unanimemente afirmaram que o maior problema do uso das TIC é que o próprio sistema educacional público estadual de Sergipe encontra-se defasado, não oferecendo acesso à rede mundial de computadores. As tecnologias utilizadas pelos professores em geral não passavam dos projetores digitais e dos sistemas de som e vídeo disponíveis na escola. E em ambos os casos os laboratórios de informática encontravam-se com problemas de funcionamento. Sendo assim, como exigir do professor adequações qualitativas em seu fazer didático-pedagógico se o poder público não cumpre seu papel de gestor?

\subsection{Existe um trabalho inter ou transdisciplinar em sua unidade de ensino voltado para o ensino da saúde? $\mathrm{E}$ as ações intersetoriais, existem?}

Novamente, os entrevistados responderam quase que unanimemente sobre a resistência de boa parte dos colegas acerca do trabalho transdisciplinar, mas este dado não necessariamente inviabiliza o trabalho dos entrevistados em busca da Promoção da Saúde e seu fazer didático-pedagógico dentro da proposta dos conteúdos programáticos para a Educação para a Saúde. Quanto ao trabalho interdisciplinar, seria necessário realizar entrevistas com os demais profissionais para analisar se estes também trabalham com o ensino da saúde em suas áreas específicas.

O Programa Saúde na Escola ocorre nos quatro municípios, mas ocorre na escola - segundo a afirmação dos entrevistados -, a ação se dá sem conexão com a proposta pedagógica da unidade e sem a compreensão do papel do educador na formação de opinião, necessitando, portanto, de ações metodológicas intersetoriais que visem reconsiderar este tipo de intervenção para que os objetivos sejam alcançados de forma mais global. Ou seja, o fazer intersetorial necessita transcorrer pelo viés da interação, promovendo comunicação entre todos os sujeitos envolvidos na proposta.

\section{CONCLUSÕES}

Estamos certos de que a enorme contribuição à formação dos nossos alunos pode ser advinda através da intervenção didático-pedagógica transdisciplinar por parte dos docentes, como também da ação intersetorial entre diferentes instituições do poder público para o fomento da Educação para a Saúde.

Esperamos ter despertado a inquietude frente à necessidade de desenvolvermos uma política educacional de promoção da saúde, compreendendo esta como um continnum composto por diferentes esferas, e não apenas a biológica, as quais, em conjunto e em inter-relação dinâmica, articulam-se promovendo alterações na relação saúde/doença no corpo, e não apenas no organismo.

Convém novamente ressaltar a relevante contribuição para a construção dessa proposta caso ocorra uma articulação dialógica com os demais agentes de outros setores públicos, como a saúde, a assistência social, segurança pública e justiça, por exemplo. 


\section{REFERÊNCIAS BIBLIOGRÁFICAS}

1. BRASIL, Secretaria de Educação Fundamental. Parâmetros Curriculares Nacionais: educação física. Brasília: MEC / SEF, 1998.

2. Freire P. Pedagogia da indignação: cartas pedagógicas e outros escritos. São Paulo: Editora UNESP, 2000.

3. Gil, A. C. Como Elaborar Projetos de Pesquisa. 4. ed. São Paulo: Atlas, 2002.

4. Thomas JR., Nelson JK., Silverman SJ. Métodos de Pesquisa em Atividade Física. 6 ${ }^{\text {a }}$ Edição. Porto Alegre: Artmed, 2012

5. Libâneo JC. Didática: novos e velhos temas. Goiânia: Edição do Autor, 2002.

6. SABROZA PC. Saúde Pública: procurando os limites da crise. Rio de Janeiro: Ensp/Fiocruz,1994. (Mimeo.).

7. Czeresnia D. Do Contágio à Transmissão: ciência e cultura na gênese do conhecimento epidemiológico. Rio de Janeiro: Editora Fiocruz, 1997.

8. Bouchard C. et al. Exercise,fitness, and health: the consensus statement. In: Bouchard C,Shephard RJ, Stephens T, Sutton JR, McPherson BD (org.) Exercise, Fitness, and Health: A Consensus of Current Knowledge. Champaign,Human Kinetics, 1990:3-28.

9. Darido SC et al. A educação física, a formação do cidadão e os parâmetros curriculares nacionais. Revista Paulista de Educação Física, São Paulo, v.15, n.1 , p.17-32, 2001.

10. Leavell S,Clarck EG. Medicina Preventiva. São Paulo: McGraw-Hill, 1976.

11. Day H, Jankey SG. Lessons from the literature: toward a holistic model of quality of life. In: RENWICK, R.; Brown I., Nagler M. Quality of life in health promotion and rehabilitation: conceptual approaches, issues and applications. Thousand Oaks: Sage, 1996.

12. WHO. Declaração Universal dos Direitos Humanos. Disponível em:< http://www.direitoshumanos.usp.br/index.php/OMS-Organiza\%C3\%A7\%C3\%A3o-Mundial-da-

Sa\%C3\%BAde/constituicao-da-organizacao-mundial-da-saude-omswho.html $>$ Acessado em 20/06/2015.

13. Araújo DSMS, Araújo CGS. Aptidão Física, Saúde e Qualidade de Vida Relacionada à Saúde em Adultos. Revista Brasileira de Medicina do Esporte. São Paulo. Vol. 6, No 5 - Set/Out, 2000.

14. Figueredo et al. A saúde na Escola: um breve resgate histórico. 15(2): 397-402, 2010. Disponível em: < http://www.scielosp.orgpdfcscv15n212.2\%20tulio.pdf >. Acessado em 26/06/2015.

15. BRASIL. Presidência da República. Casa Civil. Subchefia para Assuntos Jurídicos. Decreto nº 6.286, de 5 de dezembro de 2007. Brasília: Casa Civil, 2007.

16. Marcondes RS. Educação em saúde na escola. Revista Saúde pública. São Paulo: Editora USP, 1972. Disponível em: , < http://www.revistas.usp.brrsparticleview46346163 >. Acessado em 21/06/2015.

17. BRASIL. Constituição Federal do Brasil. Brasília: 1988. Disponível em: < http://www.planalto.gov.br/ccivil_03/constituicao/constituicao.htm>. Acessado em 01/06/2015.

18. Castells M. La Galaxia Internet. Barcelona: Areté, 2001.

19. Prensky M. Digital natives, digital immigrants part 1. On the horizon. Vol. 9. N. 05. Disponível em: < http://www.albertomattiacci.it/docs/did/Digital_Natives_Digital_Immigrants.pdf>

20. Mercado LPL. Novas tecnologias na educação: Reflexões sobre a prática. Maceió: EDUFAL, 2002.

21. Silva M. Infloexclusão e analfabetismo digital: desafios para a educação na sociedade da informação e na cibercultura. In: FREITAS, M. T. A. (Org.). Cibercultura e formação de professores. Belo Horizonte: Autêntica, 2009. (Coleção leitura, escrita e oralidade).

22. Lévy P. Cibercultura. São Paulo: Ed. 34, 1999.

23. Ramal, AC. Educação a distância: entre mitos e desafios. In: Mercado LPL (Org.). Práticas de Formação de Professores na Educação a Distância. Maceió: EDUFAL, 2008.

24. Mercado LPL. et al. Internet e suas interfaces na formação para docência online. In: Silva, Marco. (Org.). Formação de professores para docência online. São Paulo: Edições Loyola, 2012. 